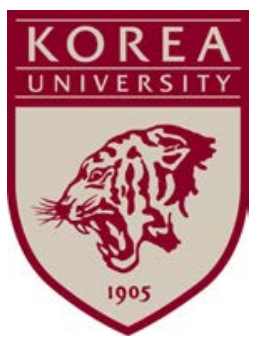

Discussion Paper Series

No. 1902

August, 2019

\title{
How People Vote in Contests: New Findings from Immortal Songs 2
}

\author{
Beomsoo Kim Sangsoo Park Yang Zhao
}

The Institute of Economic Research - Korea University

Anam-dong, Sungbuk-ku, Seoul, 136-701, South Korea, Tel: (82-2) 3290-1632, Fax: (82-2) 928-4948

Copyright (C) 2019 IER. 


\title{
How People Vote in Contests: New Findings from Immortal Songs 2
}

\author{
Beomsoo Kim¹, Sangsoo Park², Yang Zhao ${ }^{3}$
}

\begin{abstract}
Many important contests, such as job interviews and political debates, are presented in sequential order. Previous studies find serial position effects such that the later presenter has a higher probability of a win. However, no previous studies use both random assignments of contestants and a large number of contestants and judges. We use Immortal Songs 2, a popular TV program that satisfies both conditions, to confirm the findings of serial position effects. In addition, Immortal Songs 2 has round-by-round competition rules. The first round is a competition between the first and second contestants. Then, the winner of the first round is announced. The second round is a contest between the winner of the first round and the third contestant. As the rounds continue, the winner of the previous round should have a higher probability of winning in theory, but, in fact, the second contestant's probability of winning is always 0.5 .
\end{abstract}

Key Words: preference; serial position effects; step-by-step; momentary fairness bias.

\section{Number of Words: 5,626.}

Acknowledgement: Beomsoo Kim was funded by National Research Foundation of Korea (NRF2018S1A5A2A03028632)

Conflict of Interest: The authors declare that they have no conflict of interest.

\footnotetext{
1 E-mail Address: kimecon@korea.ac.kr. Phone: +82)2-3290-2204. Fax: +82)2-3290-2716. Professor, Department of Economics, Korea University, Seoul, Korea.

2 E-mail Address: starpac@korea.ac.kr. Phone: +82)2-3290-2227.

Professor, Department of Economics, Korea University, Seoul, Korea.

3 E-mail Address: zhaoyang66@korea.ac.kr. Phone: +82)10-3908-9873.

Ph.D. Candidate, Department of Economics, Korea University, Seoul, Korea.
} 


\section{Introduction}

Making decisions requires people to choose between options. In general, we often process sequentially presented information and make decisions, since people cannot simultaneously interview multiple job candidates, listen to multiple music, or watch multiple speeches (Page and Page, 2010; Li and Epley, 2009). For contestants, the outcomes of competitions, such as job interviews, political debates, and qualification trials, may an important determinant of their future careers. Each competition has its own rules to ensure that its outcomes are as fair and effective as possible. It is quite interesting and important if other factors that are independent of contestants' abilities influence the evaluation of sequentially presented individual performances.

Previous studies find that the order of appearance plays an important role in the evaluation process. Thus, the evaluation process may be biased by the order of presentation. This effect, known as the serial position effect, has been demonstrated in various situations.

In sports, Bruine de Bruin (2005, 2006) examined the international figure skating competition and found a serial position effect. Specifically, she found that scores increased for later presenters even when the presentation order was randomly decided. However, this analysis has two possible issues. First, not every competition has the same number of competitors. The number of participants ranges from 13 to 30, and the number of observations decreases quickly as the number of participants increases beyond 20. These composition changes make the results difficult to interpret. For example, in competitions among 13 participants, the last performer is the 13th rather than the 30th position. Second, although highly trained professional judges decide scores, figure skating has only 7-14 judges, which is relatively small. It is well known that a small sample may have a larger variance which means that generalizations of this finding need to be interpreted carefully.

Music is another area for which the serial position effect has been observed. Page and Page (2010) found a serial position effect using data from TV idol live shows. Unfortunately, the rules for deciding the order of presentation are not known, although the study tries to handle this issue carefully. ${ }^{1}$ As the authors suspect, we cannot rule out the possibility that the show producers put the best singer in the last position to keep viewers until the end of the program. In addition, this commercial music contest asks viewers to vote using a telephone. This voting mechanism increases the number of voters substantially, but it also creates issues. First, voter composition may be changing even during the same competition. Second, whether voters make a decision

\footnotetext{
1 The randomization test in the study assumes that each singer has a fixed quality regardless of the songs that they perform in each competition. However, this assumption is quite strong.
} 
only after watching the whole show is unclear. Fandom rather than performance may also play a role in voting, which can also be a concern. Glejser and Heyndels (2001) also found a serial position effect by using data form piano and violin versions of Queen Elisabeth Music Contest, but the number of judges was small which only have 15 judges.

To summarize, we believe that cleaner data with a better randomized presentation order and a greater number of judges are needed to quantitatively investigate the serial order effect. Our study adds to the literature by filling those gaps. We use novel data from the Korean TV Show “Immortal Songs Season 2” (Immortal Songs 2, hereafter).

These data have several advantages over the data used in previous studies. First, the assignment of presentation positions is randomized in front of the camera. Thus, performing position is independent of the characteristics of singers, the genre of songs, and other unobservable variables.

Second, the contest has five hundred (reasonably) randomly selected voters, unlike many existing studies on TV shows that use data from uncontrolled voters or on sports contests with only a few voters (i.e., judges). This rule ensures that all audience voters in the concert hall watch the show at the same time and that the maximum score for each contestant is the same, making the scores comparable between contestants.

Third, the voting occurs right after each performance rather than after all performances. This voting rule minimizes the memory effects that previous literature argued may cause the serial order effect. ${ }^{2}$

Not only do we confirm the presence of serial order effects in our data, but we also find what we call "the momentary fairness bias.” Immortal Songs 2 operates as a pairwise comparison. In the first round, the first two participants compete, and the winner is announced based on audience voting. In the second round, the winner of the first round and the third participants compete, and the winner is announced. This round-by-round competition gives us a chance to examine the step-by-step decision process for the final winner of the whole competition. We find an equal probability of each participant winning each round, and we call this result "the momentary fairness bias.” Because the previous voting counts are fixed, the number of voting counts

\footnotetext{
${ }^{2}$ Kim and Wo (2013), published in Korean, tested serial order effects using the TV program I am $a$ Vocalist. Their setting, similar to ours, has both the random assignment of performance order and a fixed number of audience voters. However, the voting mechanisms for the programs differ. In their setting, audience voters choose three singers that they like when all performances are finished. This voting mechanism may induce people to vote strategically to increase the probability of their preferred singer winning. Thus, it is hard to calculate the reference probability that is needed to calculate the exact magnitude of the bias. In addition, their show only has 30 episodes, compared to our 248 episodes.
} 
should increase to show equal probabilities of winning among two competitors in a round. ${ }^{3}$

The remainder of the paper is constructed as follows. In section 2, we explain the show in great detail. In section 3, we present simple yet very insightful statistics that are suggestive of the momentary fairness bias and provide evidence of recency effects. In section 4, we conclude.

\section{Institutional details of Immortal Songs 2}

Immortal Songs 2 is a popular TV program that has been broadcasted in Korea since June 4, 2011. Each competition chooses a famous singer from the 1970s and 1980s or a writer of melodies or lyrics as a topic. Professional singers participate as contestants, and they each prepare a song based on the topic. The total number of contestants is fixed in advance for each competition.

In early seasons of Immortal Songs 2, the competition rules were constantly changing, and they were not fully determined until February 11, 2012, when the new competition rules were implemented. This study analyzes data from Immortal Songs 2 after the implementation of the new competition rules on February 11, 2012.

Data and program-related information were collected from various online sources. We first collected data from Namu.wiki, the second-largest wiki in the Korean language. The data include competition rules, contestants and their position, competition results, and announced voting counts. To ensure the reliability of our collected data, we compared it with data compiled from Wikipedia.org, which gives more detailed explanations of the competition. When the two sources disagreed, we visited the program's website to watch the episode ourselves. The complete dataset includes all episodes broadcasted from February 11, 2012 to December 30, 2017. A total of 299 episodes were broadcast during that time. However, the episodes broadcasted on January 4, 2014, January 11, 2014, February 15, 2014 and February 22, 2014 were excluded owing to inconsistencies in competition rules ${ }^{4}$. In total, the dataset includes 1,906 performances over 295 episodes.

The performing sequence is decided by random draw. The detailed procedure is as

\footnotetext{
${ }^{3}$ We provide detail proofs in the Appendix.

${ }^{4}$ The episodes on January 4, 2012 and January 11, 2014 were recorded at one time. The competition rules took the form of one-on-one matchups instead of sequential matches. The first two contestants competed with each other, and then the next two contestants competed. The competitions for the episodes on February 15, 2014 and February 22, 2014 followed a choice rule. The first contestant was chosen by random draw, the second contestant was designated by the first contestant, and the performing sequence of the remaining contestants was specified by the winner of the previous round.
} 
follows. Balls with the name ${ }^{5}$ of each contestant are placed in a transparent box in front of the master of ceremonies (MC). The MC picks a ball from this box in front of the camera during the competition. ${ }^{6}$ When the ball with the name of the contestant is chosen, the first contestant sings a song that he or she prepared. When he or she finishes singing the song, 500 audience voters who watched the show in the concert hall vote by pressing a button if they liked the performance. Then, the total number of voters that pressed the button is automatically counted. Thus, the maximum number of votes that a contestant can receive is 500 .

After voting finishes, the MC picks a ball randomly from among the remaining balls to choose the second contestant. The same 500 audience voters vote for the second contestant as soon as he or she finishes. We call this competition between the first and second performers "round 1." When the second singer finishes singing, both competing performers stand on the stage, and all the lights are turned off. The voting result is announced by lighting up only the winner and revealing only the winner's the vote count. Vote counts for loser are not revealed.

Once everyone learns the winner of round 1 , the next round is a competition between the winner of the first round and a randomly selected third contestant. The third performer performs, but the winner of the first round does not perform again. Once the third performer finishes singing, the same 500 audience voters decide whether they liked the performance. If the third performer receives more votes than the previous round's winner received, then the third performer's votes are announced. The competition then moves to the next round until every participant has performed.

The show was broadcasted every Saturday and was recorded every Monday. However, competitions with 11 or more contestants were recorded on one day but broadcasted for two consecutive weeks. For example, the shows on March 10, 2012 and March 17, 2012 were recorded on one day. Table $\underline{1}$ displays the number of competitions by the number of contestants. The most common number of contestants is seven, followed by six.

\footnotetext{
5 The ball may contain a name or the names of contestants who will perform in a group.

${ }^{6}$ We use the terms "episode" for broadcasting and "competition" for recording. For example, when 12 contestants compete with each other, it is recorded on one day, but it is broadcasted over two episodes across two weeks.
} 
Table 1. Number of episodes by number of contestants

\begin{tabular}{cc}
\hline Number of Contestants & Number of Competitions \\
\hline 6 & 67 \\
7 & 133 \\
8 & 1 \\
11 & 5 \\
12 & 38 \\
13 & 2 \\
14 & 2 \\
Total & 248 \\
\hline
\end{tabular}

Notes: The data contain all episodes broadcasted from November 11, 2012 to December 30, 2017. The episodes broadcasted on January 4, 2014; January 11, 2014; February 15, 2014; and February 22, 2014 are excluded owing to an inconsistency in the competition rules. Sometimes, two episodes are record at a time, that is, one competition spans two episodes. In total, the dataset includes 1,906 performances over 295 episodes and 248 competitions.

Table $\underline{2}$ shows the number of competitions in each round during our study period. The data contain position two to position ten after dropping position one. Position two contains full information of win or lose related to the competition with position one. We do not include rounds 10 and above for several reasons. First, there are only 95 observations for rounds 10 and above, which is a small number of observations. Second, the fixed number of audience voters may be changing. According to reports on the internet, the recording for one episode takes a couple of hours. When two combined episodes are recorded, it takes twice as long meaning that the recording does not finish until midnight. If the recording runs too late, audience voters may decide to leave in the middle, while public transportation is still operating. In Seoul, many people use public transportation, especially when they visit the concert hall, where parking is limit. Thus, the number of voters may be less than 500 when the competition draws to a close. This difference may greatly reduce the number of votes for contestants who perform later, thus reducing their win probability.

We first present all available data in the first column. For example, we have 248 competitors in the first round combining various numbers of contestants. This data can be divided by more homogeneous group into competitions with 6 contestants, 7 contestants, and 12 contestants which is most common in the data. We present these three subgroups in the later columns. 
Table 2. Frequency and number of observations per round

\begin{tabular}{|c|c|c|c|c|}
\hline \multirow{3}{*}{$\begin{array}{l}\text { Position } \\
\text { (Round) }\end{array}$} & \multicolumn{4}{|c|}{ Number of Competitions } \\
\hline & \multirow{2}{*}{ All available data } & \multicolumn{3}{|c|}{ Grouped by total no. of contestants } \\
\hline & & 6 & 7 & 12 \\
\hline $\begin{array}{c}2 \\
(1)\end{array}$ & 248 & 67 & 133 & 38 \\
\hline $\begin{array}{l}3 \\
(2)\end{array}$ & 248 & 67 & 133 & 38 \\
\hline $\begin{array}{c}4 \\
(3)\end{array}$ & 248 & 67 & 133 & 38 \\
\hline $\begin{array}{c}5 \\
(4)\end{array}$ & 248 & 67 & 133 & 38 \\
\hline $\begin{array}{c}6 \\
(5) \\
\end{array}$ & 248 & 67 & 133 & 38 \\
\hline $\begin{array}{c}7 \\
(6)\end{array}$ & 181 & & 133 & 38 \\
\hline $\begin{array}{c}8 \\
(7)\end{array}$ & 48 & & & 38 \\
\hline $\begin{array}{c}9 \\
(8)\end{array}$ & 47 & & & 38 \\
\hline $\begin{array}{c}9 \\
(10)\end{array}$ & 47 & & & 38 \\
\hline Total & 1,563 & 335 & 798 & 342 \\
\hline
\end{tabular}

Notes: Ties occurred six times during our data period: March 3, 2012 episode rounds 1, 2, and 3; March 1,' 2014 episode round 3; October 22, 2016 episode round 5; and August 26, 2017 episode round 5 . Ties are recorded as wins for both contestants.

Although we argue that contestants are assigned randomly in front of the camera, we test this randomness in Table $\underline{3}$. The available observable characteristics for the contestants are whether they are solo or in a group and their gender. We created a binary variable for male solo performers and groups. We find that $36 \%$ of performers are male solo performers. In column 1 , the probability of a male solo performer in position 3 is one percentage point lower than that of a male solo performer in position 2 , which is $38 \%$, as shown by the constant. This difference is small in magnitude and statistically insignificant. The remaining positions also show similar results except for position 9, which has a 17 percentage point lower probability of a male solo performer, which is statistically significant. In column 2, we report using the group as a dependent variable and again show that none of the positions have statistically significant different probabilities of a group contestant relative to position 2 . We find that only 1 of the 16 estimates is statistically significant, which is around $6 \%$, close to conventional error of $5 \%$. We feel quite confident that random assignment truly occurred. 


\begin{tabular}{|c|c|c|}
\hline \multirow[b]{2}{*}{ Variables } & \multicolumn{2}{|c|}{ Dependent Variable } \\
\hline & Male Solo & Group \\
\hline \multirow[t]{2}{*}{ Position3 } & -0.0121 & 0.0363 \\
\hline & $(0.0436)$ & $(0.0432)$ \\
\hline \multirow[t]{2}{*}{ Position4 } & -0.0121 & 0.0242 \\
\hline & $(0.0436)$ & $(0.0431)$ \\
\hline \multirow[t]{2}{*}{ Position5 } & -0.0403 & 0.0363 \\
\hline & $(0.0433)$ & $(0.0432)$ \\
\hline \multirow[t]{2}{*}{ Position6 } & -0.0685 & 0.0484 \\
\hline & $(0.0428)$ & $(0.0434)$ \\
\hline \multirow[t]{2}{*}{ Position7 } & -0.00185 & -0.0168 \\
\hline & $(0.0476)$ & $(0.0462)$ \\
\hline \multirow[t]{2}{*}{ Position8 } & -0.0289 & 0.0323 \\
\hline & $(0.0758)$ & $(0.0763)$ \\
\hline \multirow[t]{2}{*}{ Position9 } & $-0.170 * *$ & -0.0449 \\
\hline & $(0.0674)$ & $(0.0734)$ \\
\hline \multirow[t]{2}{*}{ Position10 } & -0.0639 & -0.0449 \\
\hline & $(0.0749)$ & $(0.0734)$ \\
\hline \multirow[t]{2}{*}{ Constant } & $0.383 * * *$ & $0.343^{* * *}$ \\
\hline & $(0.0310)$ & $(0.0302)$ \\
\hline Dep. variable mean & 0.361 & 0.360 \\
\hline Observations & 1,563 & 1,563 \\
\hline R-squared & 0.005 & 0.003 \\
\hline \multicolumn{3}{|c|}{$\begin{array}{l}\text { Notes: The dependent variable in column } 2 \text { is Male Solo, which is an indicator } \\
\text { whether the contestant is a male solo singer. The dependent variable } \\
\text { column } 3 \text { is Group, which is an indicator for multiple performers. Stand } \\
\text { errors are in parentheses, and we report robust standard errors. *, **, and * * } \\
\text { indicate significance at the } 10 \%, 5 \% \text {, and } 1 \% \text { levels, respectively. }\end{array}$} \\
\hline
\end{tabular}

\section{Empirical Analysis}

\subsection{Serial Order Effect}

We examine serial order effects using data from Immortal Songs 2, which can overcome the concerns regarding previous studies. The results are shown in Table $\underline{4}$. In the first column, we report the final winning probability for each position using all available data following literatures. However, this result contains composition effects. In the next columns we report the final winning probability for each position using episodes with more homogeneous group like six contestants, seven contestants, and 
twelve contestants subsequently.

Table 4. Final win probabilities for each position

\begin{tabular}{|c|c|c|c|c|c|c|c|}
\hline \multirow{3}{*}{ Position } & & \multicolumn{6}{|c|}{ Grouped by the total number of contestants } \\
\hline & $\begin{array}{l}\text { All available data } \\
\text { (total obs. }=1,563 \text { ) }\end{array}$ & \multicolumn{2}{|c|}{$\begin{array}{c}6^{\mathrm{a}} \\
\text { (Obs. for each } \\
\text { position=67) }\end{array}$} & \multicolumn{2}{|c|}{$\begin{array}{c}7^{\mathrm{a}} \\
\text { (Obs. For each } \\
\text { position=133) }\end{array}$} & \multicolumn{2}{|c|}{$\begin{array}{c}12^{\mathrm{a}} \\
\text { (Obs. For each } \\
\text { position=38) }\end{array}$} \\
\hline & Estimated & $\begin{array}{c}\text { Theoretical } \\
\text { prob. }\end{array}$ & Estimated & $\begin{array}{c}\text { Theoretical } \\
\text { prob. }\end{array}$ & Estimated & $\begin{array}{c}\text { Theoretical } \\
\text { prob. }\end{array}$ & Estimated \\
\hline 1 & $\begin{array}{c}0.008 \\
(0.0067)\end{array}$ & 0.167 & $\begin{array}{c}0.015 \\
(0.0148)\end{array}$ & 0.143 & $\begin{array}{c}0.008 \\
(0.0077)\end{array}$ & 0.083 & $\begin{array}{l}0 \\
(0)\end{array}$ \\
\hline 2 & $\begin{array}{l}0.012 \\
(0.007)\end{array}$ & 0.167 & $\begin{array}{c}0.015 \\
(0.0148)\end{array}$ & 0.143 & $\begin{array}{c}0.015 \\
(0.0105)\end{array}$ & 0.083 & $\begin{array}{c}0 \\
(0)\end{array}$ \\
\hline 3 & $\begin{array}{c}0.024 \\
(0.0098)\end{array}$ & 0.167 & $\begin{array}{c}0.03 \\
(0.0208)\end{array}$ & 0.143 & $\begin{array}{c}0.03 \\
(0.0148)\end{array}$ & 0.083 & $\begin{array}{l}0 \\
(0)\end{array}$ \\
\hline 4 & $\begin{array}{c}0.093 \\
(0.0185)\end{array}$ & 0.167 & $\begin{array}{c}0.149 \\
(0.0435)\end{array}$ & 0.143 & $\begin{array}{c}0.098 \\
(0.0258)\end{array}$ & 0.083 & $\begin{array}{l}0 \\
(0)\end{array}$ \\
\hline 5 & $\begin{array}{c}0.181 \\
(0.0245)\end{array}$ & 0.167 & $\begin{array}{c}0.343 \\
(0.058)\end{array}$ & 0.143 & $\begin{array}{c}0.165 \\
(0.0322)\end{array}$ & 0.083 & $\begin{array}{l}0 \\
(0)\end{array}$ \\
\hline 6 & $\begin{array}{c}0.254 \\
(0.0277)\end{array}$ & 0.167 & $\begin{array}{c}0.463 \\
(0.0609)\end{array}$ & 0.143 & $\begin{array}{c}0.233 \\
(0.0367)\end{array}$ & 0.083 & $\begin{array}{l}0 \\
(0)\end{array}$ \\
\hline 7 & $\begin{array}{c}0.343 \\
(0.0035)\end{array}$ & & & 0.143 & $\begin{array}{c}0.459 \\
(0.0432)\end{array}$ & 0.083 & $\begin{array}{c}0.026 \\
(0.0258)\end{array}$ \\
\hline 8 & $\begin{array}{c}0.063 \\
(0.0353)\end{array}$ & & & & & 0.083 & $\begin{array}{c}0.053 \\
(0.0363)\end{array}$ \\
\hline 9 & $\begin{array}{c}0.085 \\
(0.0411)\end{array}$ & & & & & 0.083 & $\begin{array}{c}0.053 \\
(0.0363)\end{array}$ \\
\hline 10 & $\begin{array}{c}0.2978 \\
(0.0674)\end{array}$ & & & & & 0.083 & $\begin{array}{c}0.289 \\
(0.0735)\end{array}$ \\
\hline
\end{tabular}

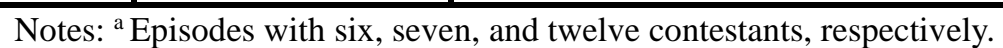

Ties for the final win occurred twice during our data period: October 22, 2016 episode round 5 and August 26, 2017 episode round 6. Ties are recorded as final wins for both contestants. Standard errors are in parentheses.

For six contestants, owing to the random assignment of contestants to positions, each position should have an equal probability of ultimately winning the competition. The first position has a winning probability of $1.5 \%$, and the winning probability increases substantially as the position increases. The sixth position, which is the last position, has a winning probability of $46.3 \%$. The latter three positions all have statistically significantly higher winning probabilities. We can calculate bias as the difference between the estimated and theoretical probabilities. Figure 1 shows the bias for each position. This result confirms previous studies' findings with clean data.

In the next column, we report the results for 133 episodes with seven contestants. 
The estimated final winning probability monotonically increases as the position approaches the last position. We find exactly the same pattern as with six contestants. In the last column, we report the results for competitions with 12 contestants. We observe no final wins up to the sixth position and then a monotonically increasing pattern. Owing to the possible composition effects of the audience voters, we report the results up to position $10 .^{7}$

Figure 1. Bias for presentation position for the final win, six contestants

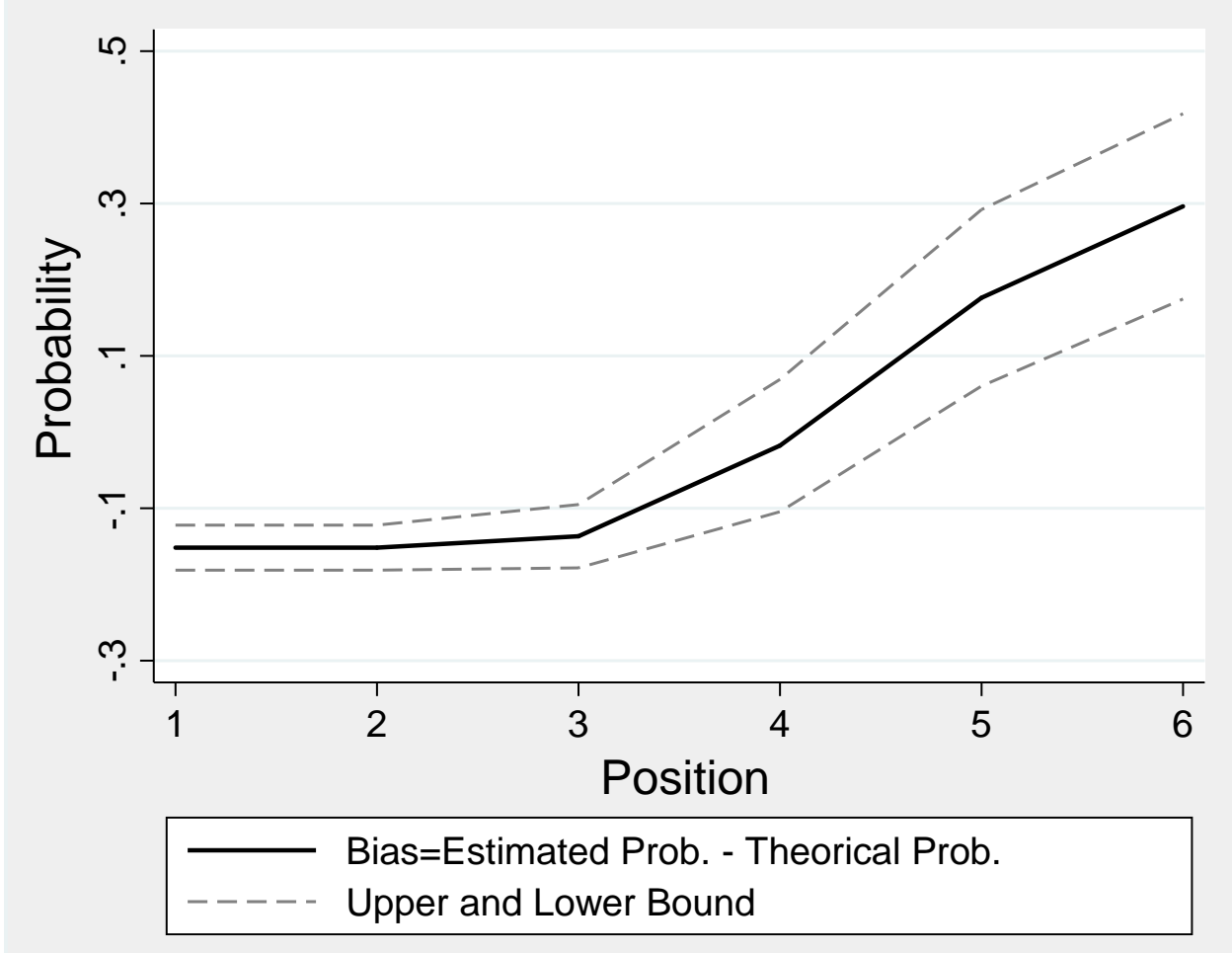

Notes: Bias is calculated as the difference between the estimated and theoretical probabilities of the final win. The confidence interval for a $95 \%$ confidence level is shown as a dotted line.

\subsection{Theoretical probability of winning for each round}

We find serial order effects within our data. We take advantage of our data's competition setup, which is a round-by-round competition. Immortal Songs 2 therefore provides a good opportunity to break the whole process down by rounds. In this section, we focus on wins in each round rather than the final win of the competition.

Based on the institutional details explained in the previous section, the voting rule for Immortal Songs 2 allows tie between competitors in each round. In an extreme

7 The eleventh position has a probability of $0.316(0.075)$, and the twelfth position has a probability of $0.263(0.071)$. Standard errors are in parentheses. 
situation, an individual voter can vote for yes for all or no performers. However, individual voters are aware of the total number of contestants in the competition. In addition, they know that the competition has one winner in the end. If no positions are particularly preferred by the audience, then the theoretical probability that the performer in the $(m+1)$-th position wins the $m$-th round approaches $1 /(m+1)$ as the size of the audience grows. The derivation of the asymptotic probabilities is given in the appendix. For example, the first round is a competition between the first and second positions. The probability of winning from the first and second position is equal and is $1 / 2$ owing to the random assignment for each position. The second round is a competition between the winner of the first round and the singer in the third position. Basically, it is a competition between three contestants. Thus, the theoretical probability of winning from the third performance position is $1 / 3$. Intuitively, the winner of the first round should be above average in performance. The same logic applies for later rounds. For example, round 6 is a competition between the winner of round 5 and the performer in the seventh performance position. The winner of round 5 received the most votes among six performers. Thus, the theoretical probability that the winner of round 5 wins round 6 is $6 / 7$.

\subsection{Empirical findings for each round}

When we calculate the probability of a win in each round for each performance position, we find stunning results.

Table $\underline{5}$ reports the probability of winning. First, we show the theoretical probability of a win, which is calculated in the previous section. For position 2, the probability of a win in round 1 is $52 \%$, which is close to the theoretical probability. The theoretical probability decreases as the position increases. In the next column, we show the observed probability in the data which stays around 0.5 all the time. For example, position 3 has a winning probability of $51.2 \%$, and that of position 4 is $52.4 \%$.

In the next columns, we report the probabilities for competitions with the same numbers of contestants, which should be more homogeneous. We report the results for six, seven, and twelve contestants. All the probabilities shown are around 0.5. 
Table 5. Theoretical and estimated win probabilities for each position by round

\begin{tabular}{|c|c|c|c|c|c|c|}
\hline \multirow[b]{2}{*}{$\begin{array}{l}\text { Position } \\
\text { (Round) }\end{array}$} & \multirow[b]{2}{*}{$\begin{array}{c}\text { Theoretical } \\
\text { Prob. }\end{array}$} & \multicolumn{2}{|c|}{ All available data } & \multicolumn{3}{|c|}{ Grouped by total no. of contestants } \\
\hline & & Estimation & Obs. & $\begin{array}{c}6 \\
\text { (Obs. for each } \\
\text { position=67) }\end{array}$ & $\begin{array}{c}7 \\
\text { (Obs. for each } \\
\text { position=133) } \\
\end{array}$ & $\begin{array}{c}12 \\
\text { (Obs. for each } \\
\text { position=38) }\end{array}$ \\
\hline $\begin{array}{c}2 \\
(1)\end{array}$ & 0.5 & $\begin{array}{c}0.520 \\
(0.032)\end{array}$ & 248 & $\begin{array}{c}0.478 \\
(0.061)\end{array}$ & $\begin{array}{c}0.526 \\
(0.0443)\end{array}$ & $\begin{array}{c}0.526 \\
(0.082)\end{array}$ \\
\hline $\begin{array}{c}3 \\
(2)\end{array}$ & 0.333 & $\begin{array}{c}0.512 \\
(0.032)\end{array}$ & 248 & $\begin{array}{c}0.478 \\
(0.061)\end{array}$ & $\begin{array}{c}0.556 \\
(0.043)\end{array}$ & $\begin{array}{c}0.421 \\
(0.081)\end{array}$ \\
\hline $\begin{array}{c}4 \\
(3)\end{array}$ & 0.25 & $\begin{array}{c}0.524 \\
(0.032)\end{array}$ & 248 & $\begin{array}{c}0.463 \\
(0.061)\end{array}$ & $\begin{array}{c}0.549 \\
(0.043)\end{array}$ & $\begin{array}{c}0.526 \\
(0.082)\end{array}$ \\
\hline $\begin{array}{c}5 \\
(4)\end{array}$ & 0.2 & $\begin{array}{c}0.536 \\
(0.032)\end{array}$ & 248 & $\begin{array}{c}0.627 \\
(0.060)\end{array}$ & $\begin{array}{c}0.489 \\
(0.044)\end{array}$ & $\begin{array}{c}0.579 \\
(0.081)\end{array}$ \\
\hline $\begin{array}{c}6 \\
(5)\end{array}$ & 0.167 & $\begin{array}{c}0.448 \\
(0.032)\end{array}$ & 248 & $\begin{array}{c}0.463 \\
(0.061)\end{array}$ & $\begin{array}{c}0.391 \\
(0.042)\end{array}$ & $\begin{array}{c}0.579 \\
(0.081)\end{array}$ \\
\hline $\begin{array}{c}7 \\
(6)\end{array}$ & 0.143 & $\begin{array}{c}0.475 \\
(0.037)\end{array}$ & 181 & & $\begin{array}{c}0.459 \\
(0.043)\end{array}$ & $\begin{array}{c}0.553 \\
(0.082)\end{array}$ \\
\hline $\begin{array}{c}8 \\
(7)\end{array}$ & 0.125 & $\begin{array}{c}0.5 \\
(0.073)\end{array}$ & 48 & & & $\begin{array}{c}0.447 \\
(0.082)\end{array}$ \\
\hline $\begin{array}{c}9 \\
(8)\end{array}$ & 0.111 & $\begin{array}{c}0.426 \\
(0.073)\end{array}$ & 47 & & & $\begin{array}{c}0.368 \\
(0.079)\end{array}$ \\
\hline $\begin{array}{l}10 \\
(9)\end{array}$ & 0.100 & $\begin{array}{c}0.468 \\
(0.074)\end{array}$ & 47 & & & $\begin{array}{c}0.474 \\
(0.082)\end{array}$ \\
\hline
\end{tabular}

Notes: Standard errors are in parentheses.

We run a linear probability model and report the results in Table $\underline{6}$. In the first column, we report the simplest model, which includes only positions. The constant indicates the probability of winning for position 2 in round 1 . The coefficient is 0.52 , which is statistically significant. We report robust standard errors. The coefficients for the other independent variables indicate the difference from position 2's winning probability. From position 3 to position 10, none of the coefficients is statistically significantly different from 0.52 .

The results in column 2 include some observable characteristics. Including the male solo or group variables may change the winning probability. The competition in each round is a competition between two contestants, and the characteristics of the opponent may also be an important factor. Thus, we include a binary variable indicating whether the opponent is a male solo performer or group. Additionally, some singers participate in the competition multiple times, and the number of appearances may contain some information, such as popularity, although the decision to participate is a mutual decision between singers and producers. We include total appearances during our data period for each contestant in log form and the opponent's total appearances in log form as well. The explanatory power of the model dramatically increases when we add more independent variables. The probability of winning for position 2 is $46.8 \%$, and position 6 has slightly lower probability of winning but is significant at the $10 \%$ level. Being a male solo performer increases the winning 
probability by 13.3 percentage points. This increase is huge considering that the winning probability as $50 \%$. By the same principle, competing with a male solo performer lowers the winning probability by 7.3 percentage points, which is also quite large. When a contestant participates in the competition multiple times, the winning probability also increases, and this difference is statistically significant although its magnitude is small. When contestants appear ten times, the probability of a win increases by $0.007 \%$.

In column 3, we control for total appearances until the previous competition in log form is rather than for total appearances during our data period. If the competition involves learning by doing, contestants' experience is accumulated until the previous competition. By the same logic, we use the opponent's total appearances measured by the same method. Even though the coefficient of total appearances until the previous competition differs in magnitude that of total appearances, the sign is the same. The same is true for the opponent's appearance measure. Our coefficient of interest does not change. In column 3, the second position has a probability of winning of 0.5 . None of the positions has a statistically different probability from 0.5 . 
Table 6. Linear probability model estimates

\begin{tabular}{|c|c|c|c|}
\hline \multirow[b]{2}{*}{ VARIABLES } & \multicolumn{3}{|c|}{ Win } \\
\hline & (1) & (2) & (3) \\
\hline \multirow[t]{2}{*}{ Constant } & $0.520 * * *$ & $0.468 * * *$ & $0.507 * * *$ \\
\hline & $(0.0318)$ & $(0.0543)$ & $(0.0499)$ \\
\hline \multirow[t]{2}{*}{ Position3 } & -0.00806 & -0.0117 & -0.00534 \\
\hline & $(0.0450)$ & $(0.0440)$ & $(0.0443)$ \\
\hline \multirow[t]{2}{*}{ Position4 } & 0.00403 & -0.00611 & 0.00713 \\
\hline & $(0.0450)$ & $(0.0445)$ & $(0.0448)$ \\
\hline \multirow[t]{2}{*}{ Position5 } & 0.0161 & 0.0168 & 0.0205 \\
\hline & $(0.0450)$ & $(0.0437)$ & $(0.0441)$ \\
\hline \multirow[t]{2}{*}{ Position6 } & -0.0726 & $-0.0737^{*}$ & -0.0630 \\
\hline & $(0.0449)$ & $(0.0444)$ & $(0.0444)$ \\
\hline \multirow[t]{2}{*}{ Position7 } & -0.0450 & -0.0516 & -0.0404 \\
\hline & $(0.0490)$ & $(0.0495)$ & $(0.0491)$ \\
\hline \multirow[t]{2}{*}{ Position8 } & -0.0202 & -0.0333 & -0.0172 \\
\hline & $(0.0791)$ & $(0.0773)$ & $(0.0783)$ \\
\hline \multirow[t]{2}{*}{ Position9 } & -0.0946 & -0.0509 & -0.0477 \\
\hline & $(0.0790)$ & $(0.0750)$ & $(0.0773)$ \\
\hline \multirow[t]{2}{*}{ Position10 } & -0.0521 & -0.0445 & -0.0312 \\
\hline & $(0.0796)$ & $(0.0790)$ & $(0.0810)$ \\
\hline \multirow[t]{2}{*}{ Male Solo } & & $0.133 * * *$ & $0.129 * * *$ \\
\hline & & $(0.0311)$ & $(0.0315)$ \\
\hline \multirow[t]{2}{*}{ Group } & & $0.0579 *$ & 0.0267 \\
\hline & & $(0.0330)$ & $(0.0328)$ \\
\hline \multirow[t]{2}{*}{ Opponent Male Solo } & & $-0.0728 * *$ & $-0.0658 * *$ \\
\hline & & $(0.0314)$ & $(0.0317)$ \\
\hline \multirow[t]{2}{*}{ Opponent Group } & & -0.0282 & -0.0182 \\
\hline & & $(0.0360)$ & $(0.0353)$ \\
\hline \multirow[t]{2}{*}{ Ln(total appearances) } & & $0.0674 * * *$ & \\
\hline & & $(0.0110)$ & \\
\hline \multirow[t]{2}{*}{ Ln(opponent's total appearances) } & & $-0.0488 * * *$ & \\
\hline & & $(0.0117)$ & \\
\hline \multirow{2}{*}{$\begin{array}{l}\text { Ln(total appearances until } \\
\text { previous competition) }\end{array}$} & & & $0.0322 * * *$ \\
\hline & & & $(0.0119)$ \\
\hline \multirow{2}{*}{$\begin{array}{l}\text { Ln(opponent's total appearances } \\
\text { until previous competition) }\end{array}$} & & & $-0.0381 * * *$ \\
\hline & & & $(0.0118)$ \\
\hline Observations & 1,563 & 1,563 & 1,563 \\
\hline R-squared & 0.004 & 0.049 & 0.031 \\
\hline
\end{tabular}

Notes: *Significance at the $10 \%$ level; **significance at the $5 \%$ level; ***significance at the $1 \%$ level 


\section{Conclusion and Discussion}

We use Immortal Songs 2, broadcasted since 2012, as an interesting experimental setting. Most previous studies of serial order effects do not have both random assignments of contestants to positions and a large number of fixed judges. Therefore, we are not sure whether serial order effect really exists. Our data alleviate these major concerns related to the prior literature. We confirm the finding of serial order effects with better data.

In addition to confirm serial order effect we can add some information using our data. One popular explanation of serial order effects is the memory effect, by which people remember recent performances better than past performances. When judges score contestants after watching all contestants, the memory effect may arise. We can rule it out in our setting, however, because people vote right after watching each performance, when their memories are vivid.

Another possible explanation relates to differing efforts by the contestants. The last contestant, who watched the previous performance, can choose his or her effort level, improving his final win probability. Although we cannot rule out this possibility, the incentive not to put forth maximum effort in our setup is hard to imagine.

We propose a new hypothesis for the momentary fairness bias. Although there is one final winner of the competition, it is a sequence of competitions between two contestants, which we call rounds. When the first contestant finishes performing, 500 voters who watched the performance in the concert hall vote for whether they liked the performance. Then, the second contestant performs, and the voting takes place. The winner of this first round and the number of votes that the winner received is announced publicly.

Then, the second round takes place. As the rounds increase, the winner of the previous round should have a higher theoretical probability of winning, but, in fact, in every round the winning probability for the second contestant is 0.5 . However, the winning probability for the second position in the second round should be $1 / 3$ because it is a competition among three contestants with random assignments. Thus, the winner in the first round has a theoretical winning probability of $2 / 3$, but our data for the second round indicate equal winning probabilities for the two contestants. We call this phenomenon momentary fairness bias, and when momentary fairness bias exists, serial order effects exist, as previous studies have shown.

One may think that the 0.5 winning probability of the second contestant in each round is indicative of people voting randomly between the winner of previous round and the second contestant. However, because the voting rule asks the audience to vote yes if they liked the second contestant's performance, the second contestant wins the 
round with probability 0.5 if he or she receives more yes votes than the immediate previous round's winner received with probability 0.5 . Thus, the 0.5 probability implies that more voters liked the second contestant in each round than liked the previous winner. We calculated exact probability to vote yes for each position to show the 0.5 probability in each round when there are 500 voters. The probability to vote yes is increasing for higher positions. (See Table $\underline{\text { A1) }}$ ).

Figure $\underline{2}$ shows the theoretical probability of a win in each round for the second position. It decreases as the round increases. However, the observed probability of a win in each round for the second position is 0.5 for all rounds. People must make decisions in these sequential presentations to choose a final winner. They might make decisions by round and choose the winner of each round with probability 0.5 even though it is a competition with a sequential presentation without rounds.

Figure 2. Winning probability of the second position by round

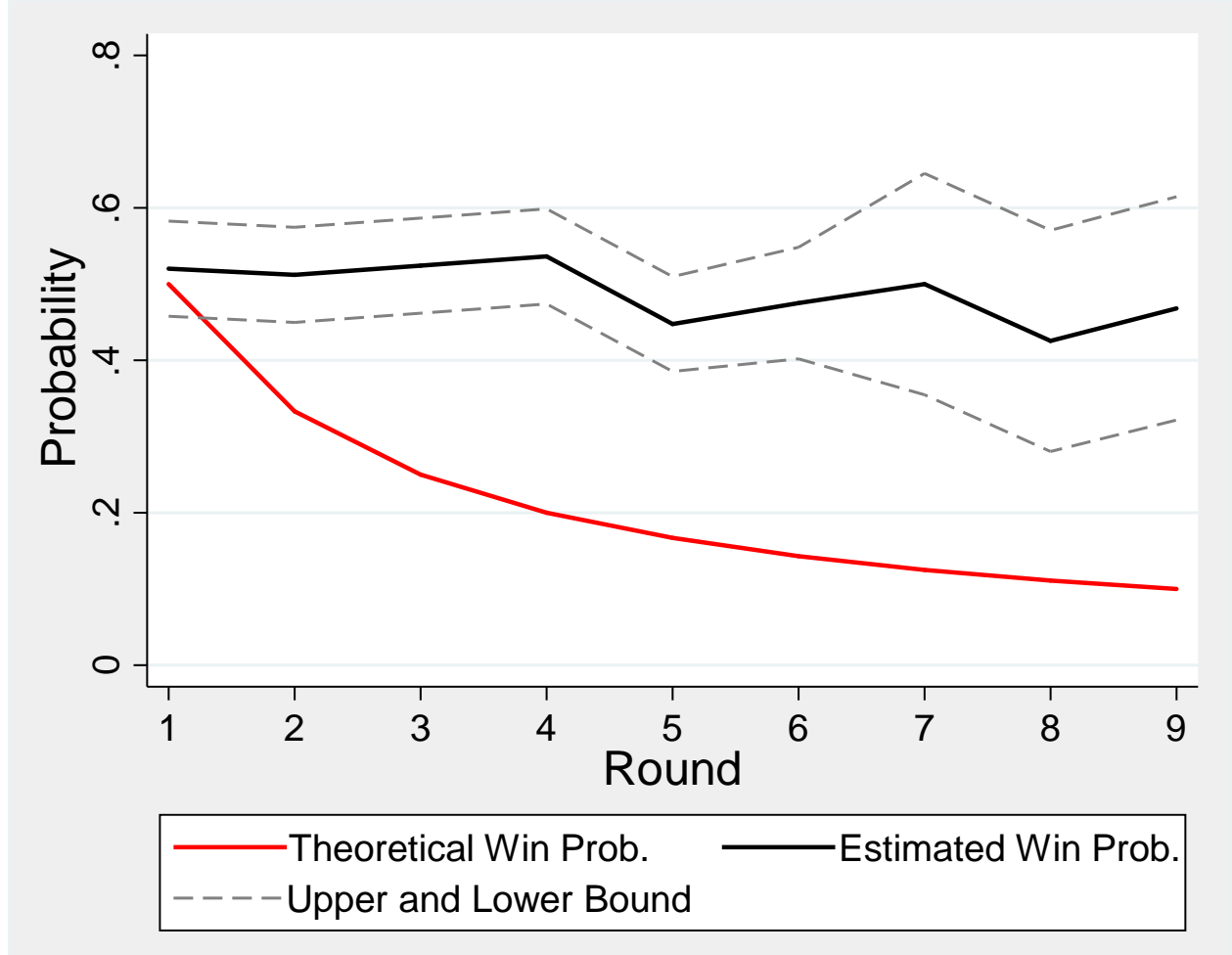

Notes: Confidence interval for the $95 \%$ confidence level is shown as a dotted line. 


\section{References}

Bruine de Bruin, W. (2005). Save the last dance for me: Unwanted serial position effects injury evaluations. Acta Psychologica, 118(3), 245-260. https://doi.org/10.1016/j.actpsy.2004.08.005

Bruine de Bruin, W. (2006). Save the last dance II: Unwanted serial position effects in figure skating judgments. Acta Psychologica, 123(3), 299-311. https://doi.org/10.1016/j.actpsy.2006.01.009

Glejser, H., \& Heyndels, B. (2001). Efficiency and inefficiency in the ranking in competitions: The case of the queen elisabeth music contest. Journal of Cultural Economics, 25(2), 109-129. https://doi.org/10.1023/A:1007659804416

Kim, D., \& Woo, S. (2013). Impact of Order on Performance in Concours: Evidence from I am a Vocalist. Kukje Kyungje Yongu, 19 (3), 57-79. http://kiss.kstudy.com/search/detail_page.asp?key=317057

Li, Y., \& Epley, N. (2009). When the best appears to be saved for last: Serial position effects on Choice. Journal of Behavioral Decision Making, 16(March), 378-389. https://onlinelibrary.wiley.com/doi/abs/10.1002/bdm.638

Page, L., \& Page, K. (2010). Last shall be first: A field study of biases in sequential performance evaluation on the Idol series. Journal of Economic Behavior and Organization, 73(2), 186-198. https://doi.org/10.1016/j.jebo.2009.08.012 


\section{Appendix A}

\section{A.1 Asymptotic final win probabilities}

We first state an assumption that is maintained throughout the analysis. Let $\left(U_{i}^{1}, \ldots, U_{i}^{m}, \ldots, U_{i}^{M}\right)$ be the utility of person $\mathrm{i}$ in the randomly collected audience of size $\mathrm{n}$ from the $\mathrm{m}$-th position singer's song in the (m-1)-th round. The voting rule is that $i$ votes for the m-th position $\left(y_{i}^{m}=1\right)$ she is sufficiently satisfied with the singer's song and does not vote for it $\left(y_{i}^{m}=0\right)$ otherwise. Assuming i's utility from the m-th position singer's song is not affected by all previous position singers' songs and that $i$ 's vote in the (m-1)-th round is solely determined by i's utility from the m-th position singer's song, we may regard $y_{i}^{m}=I\left\{U_{i}^{m}>c^{m}\right)$, where $\mathrm{I}\{\mathrm{A}\}$ is an indicator function that takes a value of one if condition $\mathrm{A}$ holds and zero otherwise and $c^{m}$ is the threshold above which $\mathrm{i}$ feels that the $\mathrm{m}$-th position singer's song was satisfactory. If we assume that $i$ treats every position equally, then we can say that $c^{m}=c$ for all m. Let $\operatorname{Pr}\left[U_{i}^{m} \leq v\right]=F(v)$. Then, without loss of generality, $\operatorname{Pr}\left[y_{i}^{m}=1\right]=\operatorname{Pr}\left[U_{i}^{m}>c\right]=1-F(c)=q$, that is, $y_{i}^{m}$ is a Bernoulli random variable with a fixed success probability $\mathrm{q}$.

Let $Y^{m}$ be the total number of votes that the m-th position receives in the (m-1)-th round. The probability that the $(\mathrm{m}+1)$-th position wins in the $\mathrm{m}$-th round is the probability that $Y^{m+1}$ is greater than or equal to all previous votes, that is, $\operatorname{Pr}\left[Y^{m+1} \geq \max _{s \leq m} Y^{s}\right]$. To derive this probability, we need the following lemmas.

Lemma 1. For every m, $\frac{1}{\sqrt{n}} \sum_{i=1}^{n}\left(y_{i}^{m}-q\right) \stackrel{p}{\rightarrow} \sigma Z_{m} \sim N\left(0, \sigma^{2}\right)$, where $\sigma:=\sqrt{q(1-q)}$ as $n \rightarrow \infty$.

Proof of lemma 1: It is obvious because $y_{i}^{m}$ is an iid Bernoulli random variable with a fixed success probability $\mathrm{q}$ for all $i$ and $\mathrm{m}$.

Lemma 2. Consider independent and identically distributed standard normal random variables $Z_{1}, Z_{2}, \ldots, Z_{m}$. Let us define $V^{(m)}:=\max _{s \leq m} Z_{s} \cdot \operatorname{Pr}\left[V^{(m)} \leq x\right]=[\Phi(x)]^{m}$ and $\frac{d}{d x} \operatorname{Pr}\left[V^{(m)} \leq x\right]=m[\Phi(x)]^{m-1} \emptyset(x)$, where $\Phi(\cdot)$ and $\emptyset(\cdot)$ are the distribution and density functions associated with the standard normal distribution. Lemma 2 is easily proved by using $\operatorname{Pr}\left[V^{(m)} \leq x\right]=\operatorname{Pr}\left[Z_{1} \leq x, Z_{2} \leq x, \ldots, Z_{m} \leq x\right]$.

Lemma 3. Consider independent and identically distributed standard normal random variables $Z_{1}, Z_{2}, \ldots, Z_{m+1}$. 
$\operatorname{Pr}\left[Z_{m+1} \geq \max _{s \leq m} Z_{s}\right]=\frac{1}{m+1}$.

Proof of Lemma 3:

$\operatorname{Pr}\left[Z_{m+1} \geq \max _{s \leq m} Z_{s}\right]=\int \operatorname{Pr}\left[Z_{m+1} \geq x \mid \max _{s \leq m} Z_{s}=x\right] m[\Phi(x)]^{m-1} \emptyset(x) d x=1-$ $m \int[\Phi(x)]^{m} \emptyset(x) d x=1-m \int_{0}^{1} u^{m} d u=\frac{1}{m+1}$.

By using Lemmas 1, 2 and 3, we can see that the following holds.

Proposition. As $\mathrm{n} \rightarrow \infty$,

$$
\begin{aligned}
& \operatorname{Pr}\left[Y^{m+1} \geq \max _{s \leq m} Y^{s}\right]=\operatorname{Pr}\left[\sum_{i=1}^{n}\left(y_{i}^{m+1}-q\right) \geq \max _{s \leq m} \sum_{i=1}^{m}\left(y_{i}^{s}-q\right)\right]= \\
& \operatorname{Pr}\left[\frac{1}{\sqrt{n r}} \sum_{i=1}^{n}\left(y_{i}^{m+1}-q\right) \geq \max _{s \leq m} \frac{1}{\sqrt{n \sigma}} \sum_{i=1}^{n}\left(y_{i}^{s}-q\right) \stackrel{p}{\rightarrow} \operatorname{Pr}\left[Z_{m+1} \geq \max _{s \leq m} Z_{s}\right]=\frac{1}{m+1}\right.
\end{aligned}
$$

Thus, the probability the $(\mathrm{m}+1)$-th position wins in the $\mathrm{m}$-th round is approximately $1 /(m+1)$ when $n$ is sufficiently large.

\section{A.2 Exact round win probabilities}

Actually, we can compute exact winning probabilities with (potentially) varying $\operatorname{Pr}\left[y_{i}^{m}=1\right]=q^{m}$. For a given audience size $\mathrm{n}$ and the number of contestants $\mathrm{m}, Y^{m}$ follows a binomial distribution with the number of trials $n$ and the probability of success $q^{m}$. Let us denote two functions: $b(s: n, q)=\left(\begin{array}{l}n \\ s\end{array}\right) q^{s}(1-q)^{n-s}$; $B(s: n, q)=\sum_{r=0}^{s} b(r: n, q)$, where $\left(\begin{array}{l}n \\ s\end{array}\right)=\frac{n !}{s !(n-s) !}$, so that $\operatorname{Pr}\left[Y^{m}=s\right]=$ $b\left(s: n, q^{m}\right)$ and $\operatorname{Pr}\left[Y^{m} \leq s\right]=B\left(s: n, q^{m}\right)$. For notational compactness, let us let $B\left(s: n, q^{m}\right)=0$ for any $s<0$ regardless of $q^{m}$. Since

$\operatorname{Pr}\left[\max _{s \leq m} Y^{s}=k\right]=\operatorname{Pr}\left[Y^{1}=k, Y^{2}=k, \cdots, Y^{m}=k\right]+\operatorname{Pr}\left[Y^{1}=k, Y^{2} \leq k-\right.$ $\left.1, \cdots, Y^{m} \leq k-1\right]+\operatorname{Pr}\left[Y^{1} \leq k-1, Y^{2}=k, \cdots, Y^{m} \leq k-1\right]+\cdots+\operatorname{Pr}\left[Y^{1} \leq k-\right.$ $\left.1, Y^{2} \leq k-1, \cdots, Y^{m}=k\right]$, we can see $\operatorname{Pr}\left[\max _{s \leq m} Y^{s}=k\right]=\prod_{r=1}^{m} b\left(k: n, q^{r}\right)+$ $\sum_{l=1}^{m} b\left(k: n, q^{l}\right) \prod_{r=1, r \neq l}^{n} B\left(k-1: n, q^{r}\right) \equiv \operatorname{bmax}\left(k: n,\left(q^{1}, q^{2}, \cdots, q^{m}\right)\right)$.

The exact probability of the $(m+1)$-th position wins at the m-th round, which we may call a $\Xi_{m+1}\left(n,\left(q^{1}, q^{2}, \cdots, q^{m+1}\right)\right)$, is

$$
\Xi_{m+1}\left(n,\left(q^{1}, q^{2}, \cdots, q^{m+1}\right)\right)=\operatorname{Pr}\left[Y^{m+1}>\max _{s \leq m} Y^{s}\right]+0.5 \operatorname{Pr}\left[Y^{m+1}=\max _{s \leq m} Y^{s}\right],
$$

where the latter term deals with tie-break situations. With given 
$\left(q^{1}, q^{2}, \cdots, q^{m}, q^{m+1}\right), \operatorname{Pr}\left[Y^{m+1}>\max _{s \leq m} Y^{s}\right]=1-\operatorname{Pr}\left[Y^{m+1} \leq \max _{s \leq m} Y^{s}\right]=1-$ $\sum_{s=0}^{n} B\left(s: n, q^{m+1}\right) \cdot \operatorname{bmax}\left(s: n,\left(q^{1}, q^{2}, \cdots, q^{m}\right)\right)$ and $\operatorname{Pr}\left[Y^{m+1}=\max _{s \leq m} Y^{s}\right]=$ $\sum_{s=0}^{n} b\left(s: n, q^{m+1}\right) \cdot \operatorname{bmax}\left(s: n,\left(q^{1}, q^{2}, \cdots, q^{m}\right)\right)$.

\section{A.3 The conundrum of 0.5}

With given $\mathrm{n}$ and $q^{1}$, we can find a $q^{2}$ such that, with the probability, the $2^{\text {nd }}$ contestant wins the first round with probability 0.5 by solving $\Xi_{2}\left(n,\left(q^{1}, q^{2}\right)\right)=0.5$.

With the $\mathrm{n}, q^{1}$, and $q^{2}$, we can solve $\Xi_{3}\left(n,\left(q^{1}, q^{2}, q^{3}\right)\right)=0.5$ to find a $q^{3}$ with which the $3^{\text {rd }}$ contestant wins the second round with probability 0.5 , and so on. Table

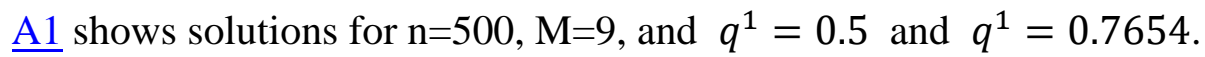

Table A1. Probability of individual's yes vote for each contestant

\begin{tabular}{c|c|c|c|c|c|c|c|c|c}
\hline $\mathrm{q}^{1}$ & $\mathrm{q}^{2}$ & $\mathrm{q}^{3}$ & $\mathrm{q}^{4}$ & $\mathrm{q}^{5}$ & $\mathrm{q}^{6}$ & $\mathrm{q}^{7}$ & $\mathrm{q}^{8}$ & $\mathrm{q}^{9}$ & $\mathrm{q}^{10}$ \\
\hline 0.5 & 0.5 & 0.5016 & 0.5141 & 0.5268 & 0.5396 & 0.5456 & 0.5568 & 0.5685 & 0.5742 \\
0.7654 & 0.7654 & 0.7654 & 0.7759 & 0.7854 & 0.7944 & 0.8033 & 0.8119 & 0.8205 & 0.8289 \\
\hline
\end{tabular}

It reads, for example, if individuals in the audience vote for yes for the $1^{\text {st }}$ contestant with probability 0.5 , then they vote for yes to subsequence contestants with 0.5, 0.5016, 0.5141, etc. Basically, in order for the 0.5 winning probabilities at each round to happen, the individuals must vote for yes more and more to the second contestant as rounds go by. 